\title{
An update in the management of malignant melanoma
}

\author{
Jayabal Pandiaraja \\ SRM Medical College Hospital and Research Centre, Chennai, Tamil Nadu, India
}

\begin{abstract}
Keywords: malignant melanoma; recent update; management
Citation: Pandiaraja J. An update in the management of malignant melanoma. J Surg Dermatol 2020; 5(2): 121; http://dx.doi.org/10.18282/jsd.v2.i1.121.
\end{abstract}

*Correspondence to: Jayabal Pandiaraja, 26/1, Kaveri Street, Rajaji Nagar, Villivakkam, Chennai, Tamil Nadu, India, dr.pandiaraja@gmail.com

Received: $8^{\text {th }}$ December 2019; Accepted: $12^{\text {th }}$ February 2020; Published Online: $26^{\text {th }}$ February 2020

\section{Introduction}

Malignant melanoma is one of the most dangerous forms of cutaneous malignancies ${ }^{[1]}$. It is classified as cutaneous melanoma and non-cutaneous melanoma based on the location of the lesion. Ultraviolet (UV) radiation exposure is a predisposing factor for cutaneous melanoma, although in other forms such as mucous and anorectal malignant melanomas, ultraviolet radiation does not play a significant role. Human papilloma virus and human retroviral infections are commonly associated with non-cutaneous melanomas ${ }^{[2]}$. Recent studies also suggested that there is an association between alcohol intake and the development of melanoma in ultraviolet spared area. This association is stronger in UV-spared areas compared to UV-exposed areas ${ }^{[3]}$. There are no proven studies as to whether vitamin D deficiency could cause cutaneous melanoma; however, studies do reveal that adjuvant vitamin $\mathrm{D}$ can be used to reduce tumor burden in melanoma ${ }^{[4]}$.

\section{Pathogenesis}

Any change in pre-existing nevi such as asymmetry, border irregularity, color change, diameter change of more than $6 \mathrm{~mm}$, and evolution or elevation can be considered as features of melanoma. Recent studies are able to identify malignant melanomas even of smaller diame- ters, called micro malignant melanomas. So, a diameter change of more than $6 \mathrm{~mm}$ is not a strict criteria for diagnosing malignant melanoma ${ }^{[5]}$. Studies showed that reactivation of TERT (Telomerase Reverse Transcriptase) is an important step in the progression of nevi to malignant melanoma ${ }^{[6]}$. Dysplastic nevi and melanocytic nevi mostly have certain gene modifications, but gene alteration alone is not sufficient for the development of melanoma $^{[7]}$. Tissue proteins such as RNA-binding protein (RBP) UNR/CSDE1, Neurotrophin Neuritin1 (NRN1), and Toll-like receptors (TLRs) 2-5, 7, 9, 10 are overexpressed in melanoma. These tissue proteins are involved in the various steps of melanoma progression such as cell migrations, vasculogenesis, local invasion, and metasta$\operatorname{sis}^{[8-10]}$.

\section{Investigations}

\section{Biopsy}

There are different opinions regarding pre-operative biopsy in malignant melanoma. Several authors recommend pre-operative excision biopsy but a few authors recommend core biopsy or punch biopsy ${ }^{[11]}$. As per current American Joint Committee on Cancer (AJCC) 2010 classification, the prognosis of malignant melanoma depends on the depth of involvement of melanoma, the presence or absence of ulcerations, and the number of

Copyright ( 2020 Pandiaraja J. This is an Open Access article distributed under the terms of the Creative Commons Attribution-Non Commercial 4.0 International License (http: //creativecommons.org/licenses/by-nc/4.0/), permitting all non-commercial use, distribution, and reproduction in any medium, provided the original work is properly cited. 
mitosis. Hence, pre-operative biopsy in suspected melanoma plays a significant role. There are problems associated with punch biopsy such as the breach of tumor mass while taking biopsy. Recent studies conducted on the outcome of punch biopsy showed that it is not going to affect long term survival.

\section{Newer tumor markers}

In the future, we can expect gene mutations to be a part of tumor classification, like testicular malignancy which has tumor markers as prognostic index, since it is going to affect the outcome. RAS signal pathway includes $N R A S$ gene mutations and $B R A F$ gene mutations. Identification of RAS mutations leads to the production of RAS and RAF inhibitors, which will be helpful in advanced or metastatic melanoma. BRAF ${ }^{V 600}, B R A^{\text {non-V600 }}$, $N R A S$, and TP53 are the common mutations detected in melanoma. BRAF mutation inhibitors (Vemurafenib, Encorafenib, and Dabrafenib) are useful in $B R A F{ }^{V 600}$ mutations but their use in $B R A F^{n o n-V 600}$ mutation is questionable ${ }^{[4]}$. Superficial spreading melanoma and nodular melanoma showed high incidence of BRAF and NRAS mutations.

MEK inhibitors (Binimetinib, Cobimetinib, and Trametinib) used along with BRAF inhibitors improve response rate, progression free survival and overall survival compared to a single agent. However, combination therapy leads to higher toxicity compared to a single agent ${ }^{[12]}$. Anti PD-1 inhibitors (Nivolumab and Pembrolizumab) are also used in melanoma.

Bcl-2 expression in malignant melanoma leads to an increase of resistance to apoptosis. So, the expression of high levels of Bcl-2 leads to poor prognosis. The c-Kit mutations are more common with acral lentigonous melanoma and mucosal melanoma. Further studies are needed to determine whether c-Kit inhibitors have any role in acral lentiginous and mucosal melanoma or not.

Eukaryotic translation initiation factor 5A2 (EIF5A2) is expressed in most of the nevi, dysplastic nevi, primary melanoma, and metastatic melanoma. EIF5A2 is inversely associated with overall survival and disease specific survival. This factor may be used as an important therapeutic marker in melanoma ${ }^{[13]}$. Detection of abovementioned mutations is recommended only for advanced stage of malignant melanoma.

\section{Mass spectrometry}

Tandem mass spectrometry using certain proteins such as 14-3-3 $\varepsilon$ isoforms and fatty acid synthase can be used to differentiate melanoma in-situ and invasive melanoma ${ }^{[14]}$.
This investigation may be useful in the near future in suspected in-situ or invasive carcinoma.

\section{Dermoscopy}

Dermoscopy is one of the important investigations for the diagnosis of melanoma. An advantage of using dermoscopy in melanoma is detecting early stages of malignant melanoma. Neutral Network Ensemble Model is a novel technique used in dermoscopy to differentiate between benign and malignant melanoma ${ }^{[15]}$.

\section{Chest x-ray}

Routine chest $\mathrm{x}$-ray alone cannot be taken as initial staging investigation for cutaneous malignant melanoma because the chance of missing metastatic melanoma is very high in routine chest $\mathrm{x}$-ray. So, it is advisable to perform higher investigation modalities such as computed tomography (CT) scan for proper work-up ${ }^{[16]}$.

\section{Management}

\section{Surgical management}

Surgical excision is the cornerstone in the management of malignant melanoma. Adequate clearance is the key for successful management of melanoma. As per current guidelines, treatment of choice for cutaneous melanoma is excision biopsy with adequate clear margin. As per National Comprehensive Cancer Network (NCCN) guidelines, the minimal requirement of clearance is $1 \mathrm{~cm}$, but clearance more than $2 \mathrm{~cm}$ is not mandatory as it is not going to improve the overall survival or disease-free interval.

\section{Sentinel lymph node biopsy}

Lymph node involvement is one of the important prognostic indicators in melanoma. Lymph node dissection of involved lymph nodes produces a poor outcome compared to lymph node dissection in sentinel lymph node biopsy. In a patient with early stage of malignant melanoma, sentinel lymph node biopsy is not mandatory. However, sentinel lymph node biopsy should be considered when the depth of involvement is more than $1 \mathrm{~mm}$.

\section{Immunotherapy}

Induced pluripotent stem cells using Sendai virus vectors is used for transforming tumor-infiltrating lymphocyte (TIL), which can be used as immunotherapy in malignant melanoma ${ }^{[17]}$. Newer drugs (Dioscin, etc.) and vectors 
are used in the management of melanoma. Dioscin could augment the bystander effect of the HSV-tk/GCV system by increasing the connexin-mediated gap junction coupling ${ }^{[18]}$. Adenovirus armed with interleukin (IL)-18 and dacarbazine can be used in advanced malignant melanoma.

\section{Metastatic disease}

Single metastasis can be treated with surgical removal or stereotactic irradiation. Non-resectable in-transit metastasis or inoperable primary tumor without metastasis can be treated with isolated limb perfusion with melphalan or TNT-alpha treatment. Recent studies showed that in-transit metastasis can be successfully treated with intensity-modulated radiotherapy (IMRT) in combination with ipilimumab or nivolumab. IMRT enhances antitumor effects of immune checkpoint inhibitors in patient with multiple in-transit metastasis ${ }^{[5]}$. Similar findings were also documented in advanced melanoma treated with ipilimumab and radiotherapy. Combination of ipilimumab with radiotherapy showed significant rate of complete response with significant overall survival ${ }^{[19]}$.

\section{Metastasectomy}

The role of metastasectomy in malignant melanoma is questionable. However, a few studies have shown its role in metastatic melanoma. Metastasectomy is only indicated when there is a long disease-free interval between the treatment of primary melanoma and metastasis or when extensive pre-operative work-up fails to identify other metastasis ${ }^{[20]}$.

\section{Conflict of interest}

The author declares no potential conflict of interest with respect to the research, authorship, and/or publication of this article.

\section{References}

1. Javabal P, Subramanian V. An unusual case of desmoplastic malignant melanoma. J Cutan Aesthet Surg 2015; 8(1): 60-63. doi: 10.4103/0974-2077.155093.

2. Jayabal P. Uncommon presentation of anorectal melanoma. Clin Cancer Invest J 2015; 4(5): 662-664. doi: 10.4103/2278-0513.162252.

3. Rivera A, Nan H, Li T, Qureshi A, Cho E. Alcohol intake and risk of incident melanoma: A pooled analysis of three prospective studies in the United States. Cancer Epidemiol Biomark Prev 2016; 25(12): 1550-1558. doi:

\subsection{8/1055-9965.EPI-16-0303.}

4. Bolerazska B, Rabajdova M, Spakova I, Marekova M. Current knowledge on the active form of vitamin D synthesized in the skin and its effects on malignant melanoma. Neoplasma 2016; 64(1). In Press. doi: 10.4149/neo_ 2017_101.

5. Jaworek-Korjakowska J. Computer-aided diagnosis of micro-malignant melanoma lesions applying support vector machines. Biomed Res Int 2016; 2016: 4381972. doi: 10.1155/2016/4381972.

6. Li Y, Cheng HS, Chng WJ, Tergaonkar V. Activation of mutant TERT promoter by RAS-ERK signaling is a key step in malignant progression of BRAF-mutant human melanomas. Proc Natl Acad Sci U S A 2016; 113(50): 14402-14407. doi: 10.1073/pnas.1611106113.

7. Melamed RD, Aydin IT, Rajan GS, Phelps R, Silvers DN, et al. Genomic characterization of dysplastic nevi unveils implications for diagnosis of melanoma. J Invest Dermatol 2016. In Press. doi: 10.1016/j.jid.2016.11.017.

8. Wurth L, Papasaikas P, Olmeda D, Bley N, Calvo GT, et al. UNR/CSDE1 drives a post-transcriptional program to promote melanoma invasion and metastasis. Cancer Cell 2016; 30(5): 694-707. doi: 10.1016/j.ccell.2016.10.004.

9. Bosserhoff AK, Schneider N, Ellmann L, Heinzerling L, Kuphal S. The Neurotrophin Neuritin1 (cpg15) is involved in melanoma migration, attachment independent growth, and vascular mimicry. Oncotarget 2016. In Press. doi: 10.18632/oncotarget.13585.

10. Coati I, Miotto S, Zanetti I, Alaibac M. Toll-like receptors and cutaneous melanoma (Review). Oncol Lett 2016; 12(5): 3655-3661. doi: 10.3892/ol.2016.5166.

11. Boland MR, Prichard RS, Bass GA, Al-Hilli Z, Levendale A, et al. Malignant melanoma: Factors affecting the surgical interval from excision biopsy to definitive surgical management. Ir J Med Sci. 2015; 184(2): 511-515.

12. Atkinson V, Long GV, Menzies AM, McArthur G, Carlino MS, et al. Optimizing combination dabrafenib and trametinib therapy in BRAF mutation-positive advanced melanoma patients: Guidelines from Australian melanoma medical oncologists. Asia Pac J Clin Oncol 2016; 12 (Suppl S7): 5-12. doi: 10.1111/ajco.12656.

13. Khosravi S, Martinka M, Zhou Y, Ong CJ. Prognostic significance of the expression of nuclear eukaryotic translation initiation factor $5 \mathrm{~A} 2$ in human melanoma. Oncol Lett 2016; 12(5): 3089-3100. doi: 10.3892/ol. 2016.5057.

14. Dowling P, Moran B, McAuley E, Meleady P, Henry M, et al. Quantitative label-free mass spectrometry analysis of formalin-fixed, paraffin-embedded tissue representing the invasive cutaneous malignant melanoma proteome. Oncol Lett 2016; 12(5): 3296-3304. doi: 10.3892/ol. 


\subsection{1.}

15. Xie FY, Fan H, Yang L, Jiang ZG, Meng RS, et al. Melanoma classification on dermoscopy images using a neural network ensemble model. IEEE Trans Med Imaging 2016. In Press. doi: 10.1109/TMI.2016.2633551.

16. Gjørup CA, Hendel HW, Pilegaard RK, Willert CB, Hölmich LR. Routine X-ray of the chest is not justified in staging of cutaneous melanoma patients. Dan Med J 2016; 63(12): A5317.

17. Saito H, Iwabuchi K, Fusaki N, Ito F. Generation of induced pluripotent stem cells from human melanoma tumor-infiltrating lymphocytes. J Vis Exp 2016; (117): e54375. doi: 10.3791/54375.
18. Xiao J, Zhang G, Li B, Wu Y, Liu X, et al. Dioscin augments HSV-tk-mediated suicide gene therapy for melanoma by promoting connexin-based intercellular communication. Oncotarget 2016. In Press. doi: 10.18632/ oncotarget.13655.

19. Koller KM, Mackley HB, Liu J, Wagner H, Talamo G, et al. Improved survival and complete response rates in patients with advanced melanoma treated with concurrent ipilimumab and radiotherapy versus ipilimumab alone. Cancer Biol Ther 2016. In Press. doi: 10.1080/15384047. 2016.1264543.

20. Lasithiotakis K, Zoras O. Metastasectomy in cutaneous melanoma. Eur J Surg Oncol 2016. In Press. doi: 10.1016/j.ejso.2016.11.001. 